\title{
Result of Endoscopic Third Ventriculostomy for Hydrocephalus Caused by Cerebral Aqueductal Stenosis in Infant Patients
}

\author{
Forhad H. Chowdhury ${ }^{1}$ Mohammod R. Haque ${ }^{2}$ Khandkar A. Kawsar ${ }^{2}$ Mainul H. Sarker ${ }^{2}$ \\ Abdul Fazal Mohammod M. Haque ${ }^{1}$
}

${ }^{1}$ Department of Neurosurgery, National Institute of Neurosciences and Hospital, Sher-e-bangla Nagar, Dhaka, Bangladesh

2 Department of Neurosurgery, Dhaka Medical College Hospital, Dhaka, Bangladesh

Address for correspondence Forhad Hossain Chowdhury, FCPS, Department of Neurosurgery, National Institute of Neurosciences and Hospital, Sher-e-bangla Nagar, Dhaka 1207, Bangladesh (e-mail: forhadchowdhury74@yahoo.com).

Indian J Neurosurg 2017;6:189-197.

\begin{abstract}
Keywords

- endoscopic third ventriculostomy

- obstructive hydrocephalus

- cerebral aqueductal stenosis

- ETV success score

- results

Background Endoscopic third ventriculostomy (ETV) is one of the important management options for hydrocephalus, especially obstructive hydrocephalus. The result of ETV in different age and etiology is quite variable according to the different authors. The study was carried out to assess the success rate of ETV as a treatment for this type of hydrocephalus in infant age group.

Material and Methods The study was done prospectively on infants (age $\leq 12$ months) admitted in the period from January 2009 to June 2013 suffering from obstructive hydrocephalus due to cerebral aqueductal stenosis (CAS). After making the diagnosis, we counseled the patient party about the probability of high failure rate of ETV in this age group and probable necessity of a second operation. With the informed consent, we performed ETV in these cases and followed up regularly in postoperative period. Control neuroimaging studies were done whenever needed (suspected failure of ETV and suspected stomal block).

Results Total 17 infants were studied. Average follow-up was 18.7 months. Twelve infants were between the age group of six and under six months while five were above six months to one year old. Fourteen (82.35\%) out of 17 patients showed overall clinical improvement. Clinical improvement was seen in two (66.6\%) infants aged 2 months or younger, three $(75 \%)$ aged $2^{+}$to 3 months, five $(100 \%)$ aged $3^{+}$to 6 months, and four $(80 \%)$ aged $6^{+}$months to 1 year. Two patients had bleeding during surgery. Three developed CSF leak through the burr hole. In one case (the patient's age was 2 months), the stoma was found blocked, and hydrocephalus returned 9 weeks after ETV. In two patients, in whom VP shunt was needed, "failed ETV" was obvious in early postoperative period. In this series, average ETV success score (ETVSS) was 52.35 (range: $40-70$ ) and overall success rate was $82.35 \%$. This indicates that ETVSS does not correlate with the outcome of ETV in infants with CAS.

Conclusion Outcome of ETV for hydrocephalus from CAS in infant is quite good and ETVSS does not correlate with the outcome.
\end{abstract}

received

November 2, 2016

accepted

July 3, 2017

published online

October 13, 2017
DOI https://doi.org/

10.1055/s-0037-1607053. ISSN 2277-954X. (c) 2017 Neurological Surgeons' Society of India
License terms

(c) (1) $\ominus$ (\$) 


\section{Introduction}

The most common therapeutic options used to treat hydrocephalus (HCP) include ventriculoperitoneal (VP) drainage and neuroendoscopic surgery. Although there are pros and cons for each option, VP shunt techniques have high complication rate $(20-80 \%){ }^{1-3}$ Endoscopic third ventriculostomy (ETV) is well accepted for obstructive hydrocephalus of various etiologies. ${ }^{4-10}$ It is considered as a better alternative to shunt surgery in obstructive HCP. Though some authors advocate ETV in patients of all ages, ${ }^{1-3,11}$ others showed that patients younger than 1 year have a higher failure rate for ETVs compared with older children. ${ }^{12}$ Therefore, we present our experience of ETV in obstructive HCP caused by congenital cerebral aqueductal stenosis (CAS), comparing between the patients below six months and above.

\section{Material and Methods}

The present study was done prospectively in the Neurosurgery Department, Dhaka Medical College Hospital, Islami Bank Central Hospital, and Ibn Sina Hospital, Dhaka, Bangladesh, on infants (age $\leq 12$ months) with obstructive HCP due to CAS, admitted in the period from January 2009 to June 2013. Failed VP shunts in CAS cases were also included. CAS patients associated with arachnoid cyst, meningocele, or myelomeningocele were excluded (to make the study homogeneous) where CAS caused triventriculomegaly. The patients who were not available for at least 6 -month follow-up were not included in the study. (Regular follow-up in a developing country such as Bangladesh is a challenging job. Availability of mobile and video phone calls helped in regular follow-ups in these cases. Sometimes we had to pay some money to the parents for meeting up their traveling cost.) For diagnosis of HCP, ultrasonogram (USG), computed tomography $(\mathrm{CT})$ scan, and magnetic resonance imaging (MRI) of the brain were used. USG of the brain was done in eight cases as a screening test by the attending physician. CT scan of the brain was done in 15 cases and MRI was done only in 2 cases because the parents were unwilling to let the infants undergo general anesthesia. After making the diagnosis, we counseled the patient's parentsy about the probability of high failure rate of ETV in this age group and probable necessity of a second operation. With the informed consent, we performed ETV in these cases. The study was carried out to assess the success rate of ETV as a treatment for this type of HCP in such age group. Patients were followed up postoperatively from days 1 through 7 ; then weekly assessment for 2 months, and then monthly assessment for 12 months followed by 3 monthly assessment of the head circumference, anterior fontanelle, cerebrospinal fluid (CSF) leak, wound infection, fever, or any other complaints. ETV was considered as successful if the patient improved clinically. Control neuroimaging studies were done whenever needed (suspected failure of ETV and suspected stomal block) or after 6 months to 1 year.

\section{Operative Technical Points}

The operative technique of ETV is standardized and is not mentioned here. After making an opening in the third ventricular floor, endoscope was advanced below through the opening to inspect further. If an imperforate membrane of Liliequist was identified, lying beneath the floor of the third ventricle was opened under direct endoscopic visualization.

If any hemorrhage was encountered during the procedure, copious warm fluid irrigation was used until all bleeding was visibly stopped and the ventricular CSF was clear. We used careful intermittent closure of outflow channel to create tamponade effect. In one patient, in whom irrigation failed to clear vision, blood-stained CSF and normal saline were aspirated by a Fogarty catheter whose tip was cut off before aspiration. After removal of endoscope with sheath, wound was closed accordingly. First dural closer was done, and then bone dust and spongostan were placed at the burr hole. Pericranial-aponeurotic layer was closed carefully. Finally skin was closed with interrupted stitches.

\section{Results}

Total 17 infants were studied, out of these 8 (47\%) were male and 9 (53\%) female. Follow-up range was 7 to 37 months (average: 18.7 months). Details of all patients are shown in - Tables 1 and 2. There were seven (41\%) infants aged 3 months or younger and three (17.6\%) were 2 months old or younger. Twelve (70.6\%) were 6 months or younger whereas five (29.4\%) were older than 6 months to 1 year. No one was born prematurely. There was history of febrile illness in the mother during pregnancy among three infants. Ten (58.8\%) infants were the first issue of the parent. One patient had history of mild birth asphyxia. Two infants had completely healthy twin siblings. Mild to moderate underweight was present in six (35\%) cases. Gross protein energy malnutrition (marasmus) was present in one case for which concurrent nutritional therapy had to given during the perioperative period of ETV. Low-birth weight (LBW) was present in three (17.6\%) cases. Three, four, five, and five infants were aged 2 months or younger, $02^{+}$to 03 months, $03^{+}$to 06 months, and $06^{+}$months to 1 year, respectively. There was no history or event of pre-ETV intraventricular hemorrhage or infection (even in failed VP shunt cases). Fourteen (82.35\%) out of 17 patients showed overall clinical improvement (-Figs. 1-3). Clinical improvement was seen in two (66.6\%) infants aged 2 months or younger, three (75\%) aged $2^{+}$to 3 months, five (100\%) aged $3^{+}$to 6 months, and four (80\%) aged $6^{+}$months to 1 year. Out of three LBW infants (all aged $<2$ months), one (33.3\%) patient failed ETV. Average age of this series was 5.5 months. The mean age of the patients with success was 5.6 months. Average ETV success score (ETVSS) of the series was 52.35. Average ETVSS was 47.5 (range: 40-50) and 64 (60-70) in infants aged 6 months or younger and $06^{+}$to 12 months age group, respectively.

Two patients had bleeding during surgery. In one case, continuous irrigation along with endoscopic tip pressure and pressure by inflated Fogarty balloon were needed to 
Table 1 Details of patients: 0-6 months of age

\begin{tabular}{|c|c|c|c|c|c|c|c|c|}
\hline $\begin{array}{l}\text { Age (mo), } \\
\text { sex and, } \\
\text { figure }\end{array}$ & $\begin{array}{l}\text { Diag- } \\
\text { nosis/ } \\
\text { ETVSS }\end{array}$ & $\begin{array}{l}\text { Pre-ETV } \\
\text { VP shunt }\end{array}$ & $\begin{array}{l}\text { H/O birth } \\
\text { asphyxia, } \\
\text { premature } \\
\text { delivery, } \\
\text { LBW, PEM }\end{array}$ & $\begin{array}{l}\text { Perioperative } \\
\text { complication }\end{array}$ & $\begin{array}{l}\text { Postoperative } \\
\text { complication }\end{array}$ & $\begin{array}{l}\mathrm{F} / \mathrm{U} \\
(\mathrm{mo})\end{array}$ & $\begin{array}{l}\text { ETV failed/ } \\
\text { Stoma } \\
\text { block }\end{array}$ & Reoperation \\
\hline $\begin{array}{l}4 / F \\
\text { (-Fig. 1) }\end{array}$ & CAS/50 & - & - & - & - & 14 & - & - \\
\hline $4 / F$ & CAS/50 & & & Bleeding & $\begin{array}{l}\text { CSF leak-LP } \\
\text { failed }\end{array}$ & 32 & Failed ETV & $\begin{array}{l}\text { Re-ETV } \\
\text { failed: VP } \\
\text { shunt done }\end{array}$ \\
\hline $3 / F$ & CAS/50 & - & - & - & - & 27 & - & - \\
\hline $23 \mathrm{~d} / \mathrm{F}$ & CAS/40 & - & LBW & - & - & 15 & - & - \\
\hline $2 / F$ & CAS/50 & - & - & - & - & 10 & - & - \\
\hline $5 / \mathrm{M}$ & CAS/50 & - & - & - & - & 7 & - & - \\
\hline $5 / M$ & CAS/40 & $\begin{array}{l}\text { Failed VP } \\
\text { shunt }\end{array}$ & - & - & - & 23 & - & - \\
\hline $\begin{array}{l}3 / F \\
\text { (-Fig. 2) }\end{array}$ & CAS/50 & - & - & Bleeding & $\begin{array}{l}\text { CSF leak- } \\
\text { healed by LP }\end{array}$ & 37 & - & - \\
\hline $3 / F$ & CAS/50 & - & - & - & Fever & 09 & - & - \\
\hline $\begin{array}{l}3 / \mathrm{M} \\
\text { (-Fig. 3) }\end{array}$ & CAS/50 & - & - & - & - & 11 & - & - \\
\hline $5 / F$ & CAS/40 & $\begin{array}{l}\text { Failed VP } \\
\text { shunt }\end{array}$ & - & - & - & 12 & - & - \\
\hline $2 / \mathrm{M}$ & CAS/50 & - & LBW & - & - & 21 & $\begin{array}{l}\text { Stoma } \\
\text { blocked- } \\
9 \text { wk after } \\
\text { ETV }\end{array}$ & $\begin{array}{l}\text { Re-ETV } \\
\text { failed: VP } \\
\text { shunt done }\end{array}$ \\
\hline
\end{tabular}

Abbreviations: CAS, cerebral aqueductal stenosis; CSF, cerebrospinal fluid; ETV, endoscopic third ventriculostomy; ETVSS, ETV success score; F/U, follow-up; F, female; LBW, low-birth weight; LP, lumbar puncture; M, male; PEM, protein energy malnutrition; VP, ventriculoperitoneal.

stop bleeding. Force aspiration through sheath channel and "cut tip Fogarty catheter" needed to make vision clear in other case. No procedure had to be abandoned. Three patients developed CSF leak through the burr hole. Leak stopped spontaneously in 3 days in one patient. One patient needed three times lumbar puncture whereas in the remaining patients (there was perioperative hemorrhage), repeated lumbar puncture and re-ETV failed to resolve the problem and finally VP shunt was needed. In one patient (age 2 months), the stoma was found blocked and HCP returned 9 weeks after ETV. As re-ETV failed in this case, the authors went for VP shunt that resolved the problem. In another case in which ETV failed (ETV was done at the age of 9 months for complication of previously done VP shunt), we had to return to VP shunt. Where VP shunt was needed, "failed ETV" was obvious in early postoperative period cases in two cases, and in the remaining cases, features of HCP reappeared 9 weeks after ETV due to stomal block. The patients' ages were was 2, 4, and 9 months at the time of ETV when VP shunts were needed. We faced no mortality, diabetes insipidus (DI), or endocrine abnormalities. Transient postoperative fever was found in three cases. ETV was done in five cases in which previously done VP shunt was failed; four out of five responded well with ETV and one needed repeat VP shunt.

\section{Discussion}

New interest developed in the use of ETV for the treatment of obstructive HCP along with advanced fiberoptic and lens technology. In recent time, the better success of third ventriculostomy could be attributed to better patient selection and improvements in endoscope, better imaging, advanced surgical technique, and instruments. ETV is considered treatment of choice in obstructive HCP. It is also now used in some communicating HCP, such as normal pressure HCP by some authors. Although ETV can be used in selected patients of all types of HCP, the success of ETV in obstructive HCP is better than that in communicating HCP. ${ }^{4}$

Obstructive HCP occurs commonly due to congenital CAS, posterior third ventricle tumor, cerebellopontine angle tumor, and other posterior fossa tumor of obstructive variety. HCPs following cerebellar infarct, Dandy-Walker malformation, syringomyelia with or without Chiari's malformation, shunt malfunction, encephalocele, craniosynostosis, and intraventricular hematoma are usually of obstructive type. Myelomeningocele with HCP, slit ventricle syndrome, and multiloculated HCPs are also of obstructive type. HCP secondary to intraventricular hemorrhage, ventriculitis, meningitis, and postoperative cases after complete excision of mass lesions are of communicating variety. Normal pressure HCP is of communicating type. When 
Table 2 Details of patients: $6^{+}-12$ months of age

\begin{tabular}{|c|c|c|c|c|c|c|c|c|}
\hline $\begin{array}{l}\text { Age (mo) } \\
\text { and sex }\end{array}$ & $\begin{array}{l}\text { Diag- } \\
\text { nosis/ } \\
\text { ETVSS }\end{array}$ & $\begin{array}{l}\text { Pre-ETV } \\
\text { VP shunt }\end{array}$ & $\begin{array}{l}\text { H/O birth } \\
\text { asphyxia, } \\
\text { premature } \\
\text { delivery, } \\
\text { LBW, PEM }\end{array}$ & $\begin{array}{l}\text { Perioperative } \\
\text { complication }\end{array}$ & $\begin{array}{l}\text { Postoperative } \\
\text { complication }\end{array}$ & $\begin{array}{l}\mathrm{F} / \mathrm{U} \\
(\mathrm{mo})\end{array}$ & Stoma block & Reoperation \\
\hline $9 / M$ & CAS/60 & $\begin{array}{l}\text { VP shunt } \\
\text { block with } \\
\text { downward } \\
\text { migration }\end{array}$ & $\begin{array}{l}\text { PEM } \\
\text { (marasmus) }\end{array}$ & - & - & 35 & - & - \\
\hline $12 / \mathrm{M}$ & CAS/70 & - & - & - & $\begin{array}{l}\text { CSF leak: } \\
\text { stopped } \\
\text { spontaneously }\end{array}$ & 21 & - & - \\
\hline $9 / M$ & CAS/60 & $\begin{array}{l}\text { CSF leak at } \\
\text { abdominal } \\
\text { end of VP } \\
\text { shunt (at } \\
\text { the age of } \\
3 \text { mo) }\end{array}$ & $\begin{array}{l}\text { Mild birth } \\
\text { asphyxia }\end{array}$ & None & None & 15 & $\begin{array}{l}\text { ETV failed } \\
\text { (failed to } \\
\text { improve } \\
\text { symptoms) }\end{array}$ & $\begin{array}{l}\text { Re-VP shunt } \\
\text { on the } \\
\text { opposite } \\
\text { side }\end{array}$ \\
\hline $12 / F$ & CAS/70 & - & - & - & - & 36 & - & - \\
\hline $9 / M$ & CAS/60 & $\begin{array}{l}\text { VP shunt: } \\
\text { at the age } \\
\text { of } 2 \mathrm{mo}\end{array}$ & - & - & Fever & 13 & - & - \\
\hline
\end{tabular}

Abbreviations: CAS, cerebral aqueductal stenosis; CSF, cerebrospinal fluid; ETV, endoscopic third ventriculostomy; ETVSS, ETV success score; F, female; F/U, follow-up; M, male; mo, month; PEM, protein energy malnutrition; VP, ventriculoperitoneal.

both the element of obstruction and the defect in the CSF absorption persist, it is complex HCP. ${ }^{4,13}$

CAS is a common cause of obstructive (noncommunicating) HCP. It could be due to congenital stenosis, acquired idiopathic, postinfectious or posthemorrhagic, and stenosis secondary to tumor. In congenital stenosis, aqueduct could be narrow or completely obstructed. Complete or near-complete obstruction usually presents in an early age, whereas if obstruction is partial, patients may be asymptomatic or present at an later age. ETV instead of a shunt placement is considered a better option for noncommunicating HCP secondary to congenital aqueductal stenosis. Results of ETV are better in congenital HCP

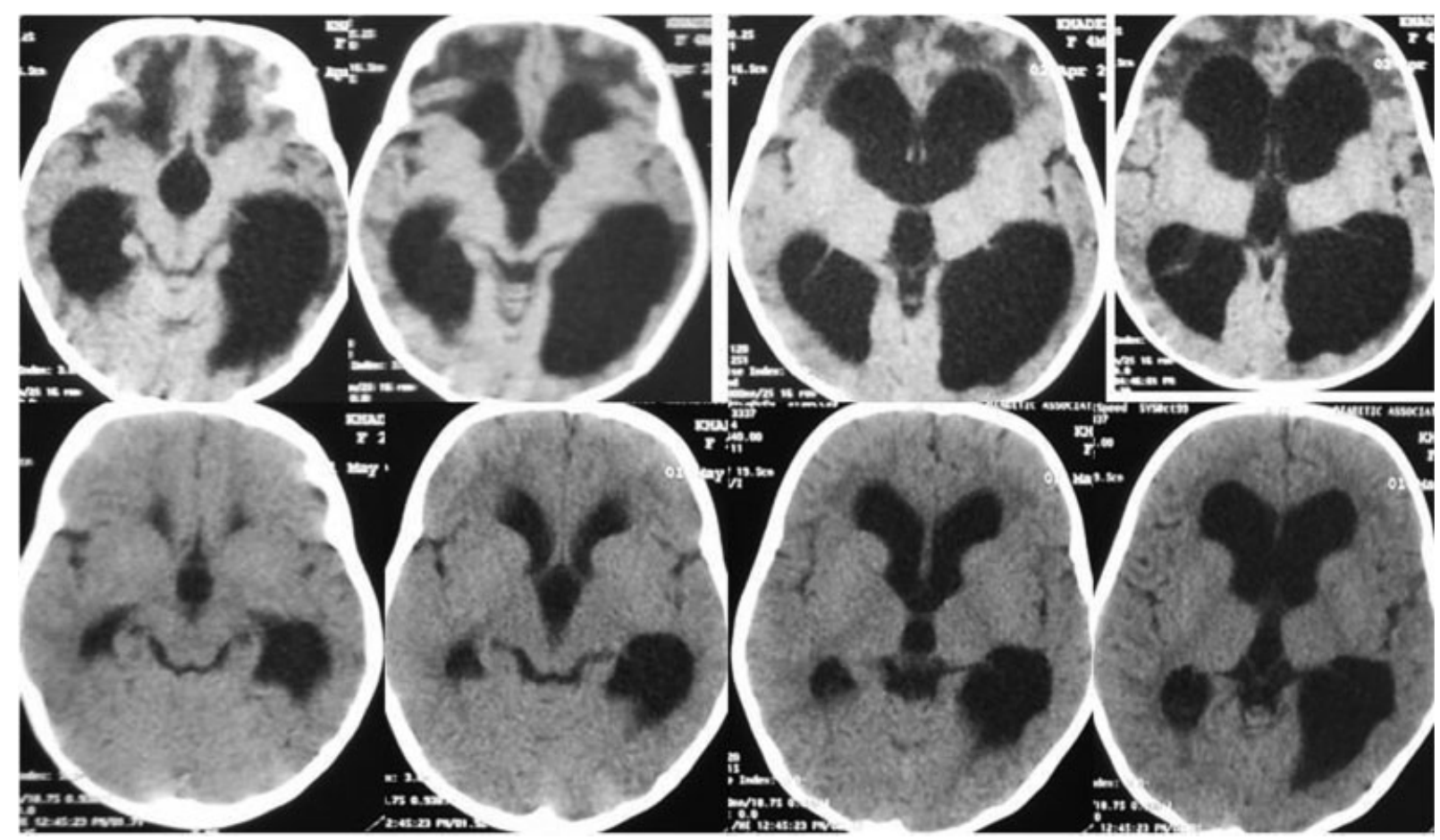

Fig. 1 Upper row-preoperative serial axial CT scan of brain showing triventriculomegaly at the age of 4 months. Lower row-postoperative serial axial CT scan of brain at the age of 2 years. CT, computed tomography. 


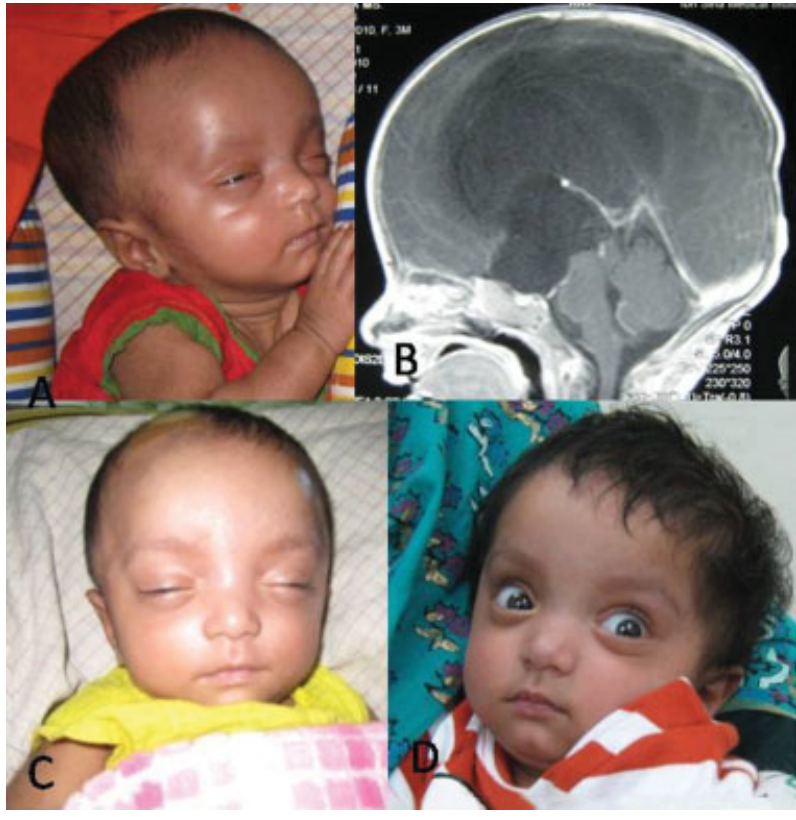

Fig. 2 (A) Preoperative picture of patient with hydrocephalus. (B) Preoperative MRI sagittal section in T1W image showing triventriculomegaly with CAS. (C) Early postoperative picture of patient after ETV. (D) Late postoperative picture of patient with successful ETV. CAS, cerebral aqueductal stenosis; ETV, endoscopic third ventriculostomy. due to aqueductal stenosis as compared with posthemorrhagic or postinfective $\mathrm{HCP}^{4,5}$ Perioperative neural injury, such as thalamic, forniceal, hypothalamic, and midbrain, are not uncommon. Intraoperative bradycardia and hemorrhages including fatal hemorrhage due to basilar artery rupture are also reported. Attempts to perforate the ventricular floor can lead to bleeding, especially in HCP following an infection and hemorrhage. From our experience, all can be easily avoided by appropriate placing of burr hole and careful surgical manipulation of endoinstruments and neurostructures. Significant side movement should be avoided to prevent bleeding due to an injury to structures, such as the fornix and veins at foramen of Monro. We did not face any neural damage except controllable bleeding per operatively. Rarely, blood might trickle from burr-hole site into the ventricle; proper hemostasis must be achieved before entering the ventricle. ${ }^{4}$ Perioperative bleeding is seen in about 3 to $8 \%^{3,14}$ of cases. Aspiration of clots and thorough irrigation of ventricular cavity should be done after bleeding stops; these measures can reduce chances of stoma closure. ${ }^{3}$ Bradycardia may occur from raised ICP due to inappropriate irrigation and brainstem stretching. ${ }^{4}$

Central nervous system infections, fever, stoma block, CSF leak, and postoperative intracranial hematomas were also seen. Postoperative mortality is also reported. ${ }^{15,16} \mathrm{DI}$, hemiparesis, gaze palsy, memory disorders, altered consciousness, weight

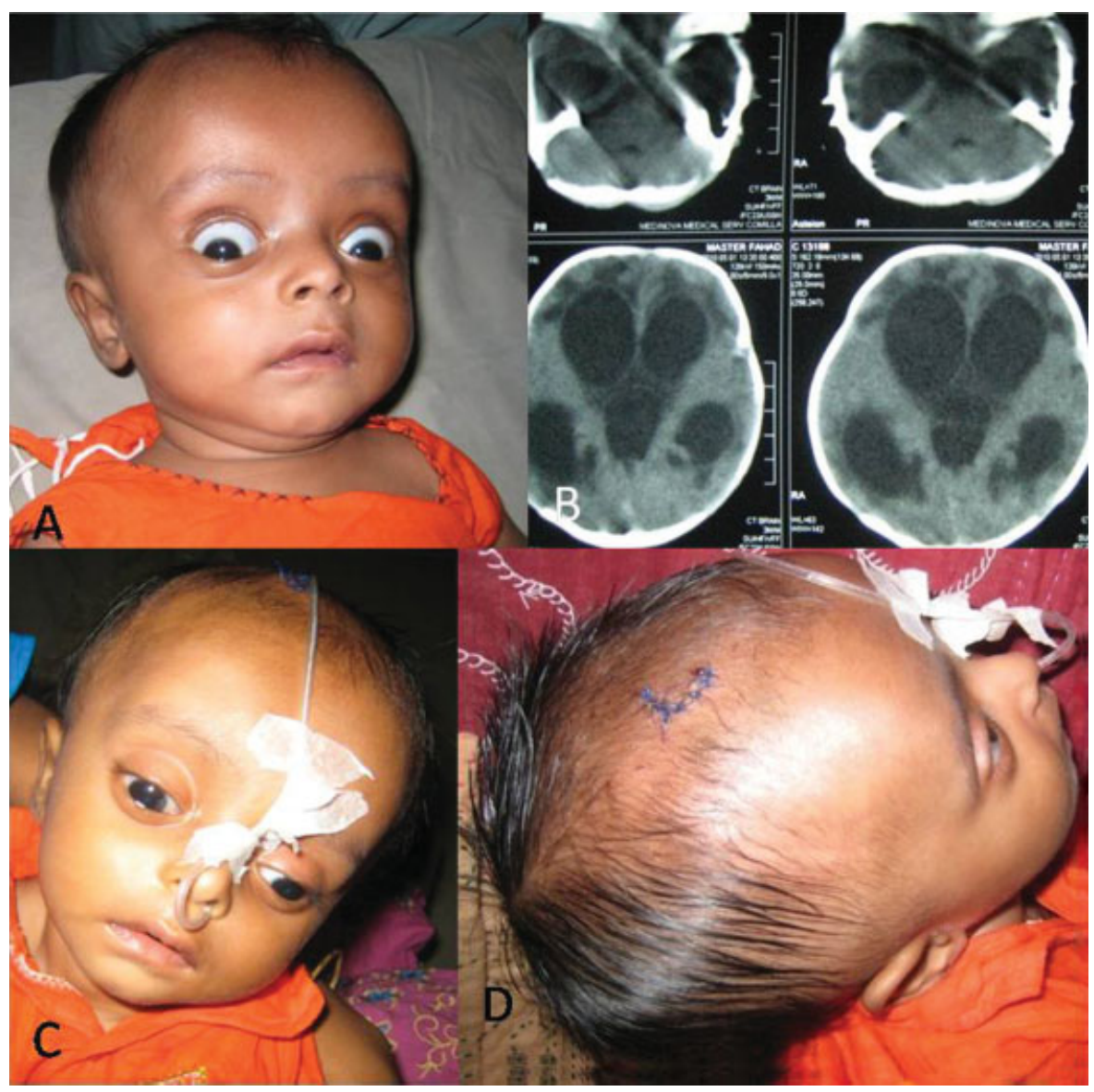

Fig. 3 (A) Preoperative picture of patient with hydrocephalus. (B) Pre-ETV CT scan axial sections showing triventriculomegaly due to CAS. (C, D) Early postoperative pictures of patient with successful ETV. CAS, cerebral aqueductal stenosis; CT, computed tomography; ETV, endoscopic third ventriculostomy. 
gain, precocious puberty, and abnormal prolactin levels can occur after ETV. However, abnormal prolactin levels are not clinical significant. ${ }^{17}$ DI was reported by Choi et $\mathrm{al}^{18}$ in $3 \%$ cases. Chronic subdural hematoma or subdural hygroma can occur after ETV. Rare complications such as postoperative hyperkalemia, severe parkinsonism, acute respiratory alkalosis, and tachypnea can occur after ETV. Overall complication rate after ETV is about 2 to $15 \%$, but the permanent complications are few. ${ }^{4,19-21}$

Postoperative fever could occur due to use of electrocautery, which should be avoided. We faced postoperative fever in three cases that subsided spontaneously. Postoperative CSF leak could be avoided by plugging cortical and dural opening by Gelfoam, direct dural closure, especially in large ventriculomegaly in infants, or by using artificial dural substitute and tissue sealant in at-risk patients. Postoperative CSF leak can also be reduced by galeal-pericranial flap. ${ }^{4,22}$ Incidence of CSF leak after ETV have varied between 2 and 7\%. In the series of Yadav et al, CSF leak occurred in $16 \%$ patients in whom half of the cases of CSF leak stopped spontaneously. The causes of persistent leak include closure of stoma, failure of closure of the dura, thinnedout scalp, and thin cortical mantle in patients with gross HCP. Dura closer should be done properly, especially in patients with gross HCP with thin cortical mantle. ${ }^{3}$ Postoperative complications in the ETV patients usually occur within 1 month after operation. However, delayed complications including stoma block can occur. Delayed stoma block, though very rare, can be fatal. ${ }^{23}$ Intraoperative observation of thickened arachnoid membranes at the level of the interpeduncular cisterns at the time of ETV should be considered a significant risk of stoma block. ${ }^{24}$ Postoperative failures usually occur early; regular clinical and radiologic follow-up must be performed, especially in the first years after the ETV. ${ }^{25}$ According to Mohanty et $\mathrm{al}^{26}{ }^{26}$ reclosure of the stoma because of gliosis and scarring has been observed in 6 to $15 \%$ of ETV failures. The high rate of reclosure in infants can be explained as follows: as CSF absorption is impeded, there is a greater tendency for the development of new arachnoid membranes in infants, and there is also growth of gliotic, ependymal, and scar tissue. ${ }^{12}$ ICP monitoring with or without external ventricular drainage during the immediate postoperative period after ETV could be required in patients who continue to have clinical features of raised ICP or failed to show an improvement after ETV. Few patients fail to show an improvement despite patent stoma after ETV. CSF drainage by lumbar puncture helps by increasing the compliance and the buffering capacities of the spinal subarachnoid spaces. It probably decreases the CSF outflow resistance from the ventricular system, facilitates the decrease in the ventricular volume, and allows faster permeation of CSF in the intracranial subarachnoid spaces. A cycle of one to three lumbar punctures should always be performed in patients who remain symptomatic after ETV, before ETV is assumed to have failed. ${ }^{4,27-29}$

A reduction in the ventricular size detected soon after ETV is associated with a good clinical outcome. This decrease in ventricular size continues during the first few months after surgery. Reduction in the size of third ventricle width is more than that in lateral ventricle size width after successful
ETV. Magnetic resonance ventriculography was effective in assessing subarachnoid space and stoma patency after ETV. T2-weighted turbo inversion-recovery magnetic resonance images can detect flow-void sign better. Cine phase-contrast (PC) MRI is useful even if no flow void is seen. Cine PC MRI may be used to determine the patency of the stoma and may be used in follow-up. 4,24,30,31

Determining the best candidates for ETV has been difficult, with conflicting reports on who are the best candidates, particularly regarding the effect of age and etiology. Reports have indicated that outcome is a function of age $\mathrm{e}^{23,32,33}$ independent of age, ${ }^{1,34}$ a function of etiology, ${ }^{1,35-37}$ or a function of both age and etiology. ${ }^{38}$ More recent evidence from larger, and in one case, multicenter series has supported the finding that age is the main determinant of outcome with younger children, particularly neonates, faring worse. ${ }^{39,40}$ The other standard technique of CSF diversion, a CSF shunt, has rarely been compared with ETV, with results suggesting no difference $^{41}$ or a slight advantage in terms of costeffectiveness for ETV. ${ }^{42}$ CSF shunt outcomes are also known to be influenced by age, with younger children also faring more poorly. ${ }^{43-45}$

There are controversies regarding the success of ETV in infants. Some authors reported poor results, especially in neonates and in infants younger than 2 months. ${ }^{4}$ Shim et $\mathrm{al}^{46}$ suggested that simultaneous ETV and VP shunt should be performed in infantile HCP due to poor results of ETV alone. The higher clinical success rate of ETV in the series by Yadav et al was $83.7 \%{ }^{3}$ Success rates of $71 \%,{ }^{47} 64 \%,{ }^{48}$ and $85 \%{ }^{49}$ were observed in other studies done in infants whereas the success rates varied from $76^{14}$ to $91.5 \%$ in other age group patients. ${ }^{18}$ They found that failure rate of ETV in LBW premature infants was higher (60\%) as compared to full-term normal-birth-weight infants $(12.3 \%) .^{3}$ In the case of children under 1 year, long-term shunt independence was $75 \%$ in the series by Stan et al. ${ }^{50}$ The success of these patients was influenced much by the technique used. In the absence of plexus coagulation, the success rate of the operation is significantly reduced. The study by Warf et al proved the difference in the success rate with $48.6 \%$ in patients in whom they practiced only ETV compared to $81.9 \%$ in those in whom they practiced ETV and plexus coagulation both. ${ }^{51}$ Kulkarni et al $^{52}$ reported the relative higher risk of initial failure in ETV than shunt in children. The relative risk becomes progressively lower for ETV after about 3 months. Patients could experience a longterm treatment survival advantage after an early high-risk period of ETV failure as compared to shunt. They observed that it might take several years, however, to realize this benefit. There have been several studies of the effectiveness of ETV in children under two years of age. Kadrian et al reported a strong effect of the patient's age on outcome. ${ }^{40}$ The authors reported the percentages of patients "presumed to have a functioning ETV after 5 years" as follows: $41 \%$ in patients 1 - to 6 -month old at the time of surgery, $58 \%$ in patients 6 - to 24 -month old, and more than $70 \%$ in patients older than 24 months. These results correspond to the data reported by other authors. ${ }^{32}$ However, Javadpour et $\mathrm{al}^{47}$ 
Table 3 Comparative success rate of ETV in aqueductal obstruction by some published series

\begin{tabular}{|c|c|c|c|}
\hline Series & No. of patients & Age group & $\begin{array}{l}\text { Result of success } \\
\text { rate (\%) }\end{array}$ \\
\hline Fritsch et al $(2005)^{1}$ & 3 & Pediatric $(<1 \mathrm{y})$ & 100 \\
\hline Cinalli et al (1999) ${ }^{11}$ & 119 & Pediatric & 72 \\
\hline Zohdi et al $(2013)^{12}$ & 08 & Pediatric & 12.5 \\
\hline Gangemi et al $(2007)^{25}$ & 88 & Pediatric plus adult & 87 \\
\hline Drake $(2007)^{39}$ & 107 & Pediatric & $\begin{array}{l}65 \text { and } 52 \text { success rates at } 1 \text { and } \\
5 \mathrm{y} \text {, respectively }\end{array}$ \\
\hline Tuli et al (1999) & 32 & Pediatric & 56 \\
\hline Gorayeb et al $(2004)^{48}$ & 11 & Pediatric $(<1 \mathrm{y})$ & 55 \\
\hline Warf et al $(2005)^{51}$ & 153 & Pediatric & $\begin{array}{l}53 \text { in all patients and } 70 \text { in } \\
\text { aqueductal obstruction }\end{array}$ \\
\hline Fukuhara et al $(2000)^{57}$ & 37 & Pediatric plus adult & 68 \\
\hline Bognar et al $(2005)^{58}$ & 76 & Pediatric plus adult & 71 \\
\hline Koch-Wiewrodt and Wagner $(2006)^{59}$ & 13 & Pediatric (< 1 y) & 54 \\
\hline Sacko et al (2010) 60 & 350 & Pediatric plus adult & 61 \\
\hline
\end{tabular}

Abbreviation: ETV, endoscopic third ventriculostomy; y, year.

reported ETV success rate of 33\% (continued patency during follow-up in 7 of 21 patients) and found that success depended on etiology rather than on patient age. Baldauf et $\mathrm{al}^{38}$ reported 50\% success rate in idiopathic aqueductal stenosis. Analysis of the success and failure of ETV in infants in the Netherlands confirmed that ETV should be considered as an initial treatment that carries a low risk of morbidity in these infants. As the immune system rapidly matures, postponing shunt implantation for several months or even weeks would make ETV worthwhile. Moreover, the authors noted that a second ETV should always be considered before shunt placement in young patients with a failed ETV, as the probability of ETV success rapidly increases 4 months after birth. $^{53}$ The largest study of ETV success in very young children was conducted in Uganda and it involved 153 children younger than 1 year. ${ }^{54}$ The ETV success rate among these patients was $53 \%$. The surgery success rates for patients with aqueductal obstruction were $70 \%$. Fritsch et al, ${ }^{1}$ reporting a $39 \%$ ETV success rate, presented ETV as an effective alternative for the treatment of obstructive HCP in infants younger than 1 year. Korean authors have reported simultaneous implantation of a VP shunt and ETV as the first choice of treatment for hydrocephalic patients younger than 1 year (83.9\% success rate). Perhaps placement of the ventricular catheter in the prepontine cistern under endoscopic guidance reduces the risk of stoma closure and development of new arachnoid membranes. ${ }^{55}$ On the other hand, these combined procedures do not provide patients with shunt independence and or freedom from shunt complications. $^{12}$ In the small series of ETV under the age of 6 months in obstructive HCP due to CAS, Zodi et al found very low success rate (only $12.5 \%$ cases were successful). ${ }^{12}$

Success rates of ETV in different series are shown in (-Table 3). ${ }^{1,11,12,25,39,41,48,51,56-60}$ ETVSS is used to predict the outcome of ETV before operation. ${ }^{52}$ In this series, average ETVSS was 52.35 (range: 40-70) and overall success rate was $82.35 \%$. This indicates that ETVSS does not correlate with the outcome of ETV in infants with CAS. In our series, we did not find any impact of age on the success of ETV in CAS. In this small series, success rate of ETV in CAS under the age of 1 year was not low (82.35\%) without choroid plexus coagulation. It is not well understood; result of success in ETV in obstructive HCP in infant was so variable in different series. During operation the authors frequently noticed extra-arachnoidal membrane after fenestration of third ventricular floor; the authors went for fenestration of that membrane(s) almost routinely to the anterior surface of the basilar artery. In future, larger series with more number of cases will probably answer the question preciously.

\section{Conclusion}

Outcome of ETV for HCP from CAS in infant is quite good with low risk of complication even in very young infant, and ETVSS does not correlate with the outcome.

\section{References}

1 Fritsch MJ, Kienke S, Ankermann T, Padoin M, Mehdorn HM. Endoscopic third ventriculostomy in infants. J Neurosurg 2005; 103(1, Suppl):50-53

2 Pereira J, Lamas R, Ayres-Basto M, Seixas ML, Vaz R. [Neuroendoscopy in the treatment of obstructive hydrocephaly] [in Portuguese]. Acta Med Port 2002;15(05):355-364

3 Yadav YR, Jaiswal S, Adam N, Basoor A, Jain G. Endoscopic third ventriculostomy in infants. Neurol India 2006;54(02):161-163

4 Yadav YR, Parihar V, Pande S, Namdev H, Agarwal M. Endoscopic third ventriculostomy. J Neurosci Rural Pract 2012;3(02):163-173

5 van Beijnum J, Hanlo PW, Fischer $K$, et al. Laser-assisted endoscopic third ventriculostomy: long-term results in a series 
of 202 patients. Neurosurgery 2008;62(02):437-443, discussion 443-444

6 Mohanty A, Santosh V, Devi BI, Satish S, Biswas A. Efficacy of simultaneous single-trajectory endoscopic tumor biopsy and endoscopic cerebrospinal fluid diversion procedures in intra- and paraventricular tumors. Neurosurg Focus 2011;30(04):E4

7 Morgenstern PF, Osbun N, Schwartz TH, Greenfield JP, Tsiouris AJ, Souweidane MM. Pineal region tumors: an optimal approach for simultaneous endoscopic third ventriculostomy and biopsy. Neurosurg Focus 2011;30(04):E3

8 Al-Tamimi YZ, Bhargava D, Surash S, et al. Endoscopic biopsy during third ventriculostomy in paediatric pineal region tumours. Childs Nerv Syst 2008;24(11):1323-1326

9 Oppido PA, Fiorindi A, Benvenuti L, et al. Neuroendoscopic biopsy of ventricular tumors: a multicentric experience. Neurosurg Focus 2011;30(04):E2

10 Roopesh Kumar SV, Mohanty A, Santosh V, et al. Endoscopic options in management of posterior third ventricular tumors. Childs Nerv Syst 2007;23(10):1135-1145

11 Cinalli G, Sainte-Rose C, Chumas P, et al. Failure of third ventriculostomy in the treatment of aqueductal stenosis in children. J Neurosurg 1999;90(03):448-454

12 Zohdi AZ, El Damaty AM, Aly KB, El Refaee EA. Success rate of endoscopic third ventriculostomy in infants below six months of age with congenital obstructive hydrocephalus (a preliminary study of eight cases). Asian J Neurosurg 2013;8(03):147-152

13 Yadav YR, Mukerji G, Parihar V, Sinha M, Pandey S. Complex hydrocephalus (combination of communicating and obstructive type): an important cause of failed endoscopic third ventriculostomy. BMC Res Notes 2009;2:137

14 Hopf NJ, Grunert P, Fries G, Resch KD, Perneczky A. Endoscopic third ventriculostomy: outcome analysis of 100 consecutive procedures. Neurosurgery 1999;44(04):795-804, discussion 804-806

15 Erşahin Y, Arslan D. Complications of endoscopic third ventriculostomy. Childs Nerv Syst 2008;24(08):943-948

16 Bouras T, Sgouros S. Complications of endoscopic third ventriculostomy. J Neurosurg Pediatr 2011;7(06):643-649

17 Fritsch MJ, Bauer M, Partsch CJ, Sippell WG, Mehdorn HM. Endocrine evaluation after endoscopic third ventriculostomy (ETV) in children. Childs Nerv Syst 2007;23(06):627-631

18 Choi JU, Kim DS, Kim SH. Endoscopic surgery for obstructive hydrocephalus. Yonsei Med J 1999;40(06):600-607

19 Bernard R, Vallee F, Mateo J, et al. Uncontrollable high-frequency tachypnea: a rare and nearly fatal complication of endoscopic third ventriculostomy: case report and literature review. Minim Invasive Neurosurg 2010;53(5-6):270-272

20 Akiyama T, Tanizaki Y, Akaji K, et al. Severe parkinsonism following endoscopic third ventriculostomy for non-communicating hydrocephalus-case report. Neurol Med Chir (Tokyo) 2011; 51(01):60-63

21 Sung HJ, Sohn JT, Kim JG, et al. Acute respiratory alkalosis occurring after endoscopic third ventriculostomy-a case report. Korean J Anesthesiol 2010;59(Suppl):S194-S196

22 Mohanty A, Suman R. Role of galeal-pericranial flap in reducing postoperative CSF leak in patients with intracranial endoscopic procedures. Childs Nerv Syst 2008;24(08):961-964

23 Lipina R, Palecek T, Reguli S, Kovarova M. Death in consequence of late failure of endoscopic third ventriculostomy. Childs Nerv Syst 2007;23(07):815-819

24 Faggin R, Calderone M, Denaro L, Meneghini L, d'Avella D. Longterm operative failure of endoscopic third ventriculostomy in pediatric patients: the role of cine phase-contrast MR imaging. Neurosurg Focus 2011;30(04):E1

25 Gangemi M, Mascari C, Maiuri F, Godano U, Donati P, Longatti PL. Long-term outcome of endoscopic third ventriculostomy in obstructive hydrocephalus. Minim Invasive Neurosurg 2007; 50(05):265-269
26 Mohanty A, Vasudev MK, Sampath S, Radhesh S, Sastry Kolluri VR. Failed endoscopic third ventriculostomy in children: management options. Pediatr Neurosurg 2002;37(06):304-309

27 Elgamal EA. Continuous monitoring of intracranial pressure after endoscopic third ventriculostomy in the management of CSF shunt failure. Minim Invasive Neurosurg 2010;53(02):49-54

28 Lee SH, Kong DS, Seol HJ, Shin HJ. Endoscopic third ventriculostomy in patients with shunt malfunction. J Korean Neurosurg Soc 2011;49(04):217-221

29 Yadav YR, Parihar V, Sinha M. Lumbar peritoneal shunt. Neurol India 2010;58(02):179-184

30 Santamarta D, Martin-Vallejo J, Díaz-Alvarez A, Maillo A. Changes in ventricular size after endoscopic third ventriculostomy. Acta Neurochir (Wien) 2008;150(02):119-127, discussion 127

31 Singh I, Haris M, Husain M, Husain N, Rastogi M, Gupta RK. Role of endoscopic third ventriculostomy in patients with communicating hydrocephalus: an evaluation by MR ventriculography. Neurosurg $\operatorname{Rev} 2008 ; 31(03): 319-325$

32 Koch D, Wagner W. Endoscopic third ventriculostomy in infants of less than 1 year of age: which factors influence the outcome? Childs Nerv Syst 2004;20(06):405-411

33 Wagner W, Koch D. Mechanisms of failure after endoscopic third ventriculostomy in young infants. J Neurosurg 2005;103(1, Suppl): 43-49

34 O'Brien DF, Seghedoni A, Collins DR, Hayhurst C, Mallucci CL. Is there an indication for ETV in young infants in aetiologies other than isolated aqueduct stenosis? Childs Nerv Syst 2006;22(12): 1565-1572

35 Beems T, Grotenhuis JA. Is the success rate of endoscopic third ventriculostomy age-dependent? An analysis of the results of endoscopic third ventriculostomy in young children. Childs Nerv Syst 2002;18(11):605-608

36 Etus V, Ceylan S. Success of endoscopic third ventriculostomy in children less than 2 years of age. Neurosurg Rev 2005;28(04): 284-288

37 Feng H, Huang G, Liao X, et al. Endoscopic third ventriculostomy in the management of obstructive hydrocephalus: an outcome analysis. J Neurosurg 2004;100(04):626-633

38 Baldauf J, Oertel J, Gaab MR, Schroeder HW. Endoscopic third ventriculostomy in children younger than 2 years of age. Childs Nerv Syst 2007;23(06):623-626

39 Drake JM; Canadian Pediatric Neurosurgery Study Group. Endoscopic third ventriculostomy in pediatric patients: the Canadian experience. Neurosurgery 2007;60(05):881-886, discussion 881-886

40 Kadrian D, van Gelder J, Florida D, et al. Long-term reliability of endoscopic third ventriculostomy. Neurosurgery 2005;56(06): 1271-1278, discussion 1278

41 Tuli S, Alshail E, Drake J. Third ventriculostomy versus cerebrospinal fluid shunt as a first procedure in pediatric hydrocephalus. Pediatr Neurosurg 1999;30(01):11-15

42 Garton HJ, Kestle JR, Cochrane DD, Steinbok P. A costeffectiveness analysis of endoscopic third ventriculostomy. Neurosurgery 2002;51(01):69-77, discussion 77-78

43 Tuli S, Drake J, Lawless J, Wigg M, Lamberti-Pasculli M. Risk factors for repeated cerebrospinal shunt failures in pediatric patients with hydrocephalus. J Neurosurg 2000;92(01):31-38

44 Tuli S, O'Hayon B, Drake J, Clarke M, Kestle J. Change in ventricular size and effect of ventricular catheter placement in pediatric patients with shunted hydrocephalus. Neurosurgery 1999; 45(06):1329-1333, discussion 1333-1335

45 Drake JM, Kulkarni AV, Kestle J. Endoscopic third ventriculostomy versus ventriculoperitoneal shunt in pediatric patients: a decision analysis. Childs Nerv Syst 2009;25(04):467-472

46 Shim KW, Kim DS, Choi JU. Simultaneous endoscopic third ventriculostomy and ventriculoperitoneal shunt for infantile hydrocephalus. Childs Nerv Syst 2008;24(04):443-451 
47 Javadpour M, Mallucci C, Brodbelt A, Golash A, May P. The impact of endoscopic third ventriculostomy on the management of newly diagnosed hydrocephalus in infants. Pediatr Neurosurg 2001;35(03):131-135

48 Gorayeb RP, Cavalheiro S, Zymberg ST. Endoscopic third ventriculostomy in children younger than 1 year of age. J Neurosurg 2004;100(5, Suppl Pediatrics):427-429

49 Buxton N, Macarthur D, Mallucci C, Punt J, Vloeberghs M. Neuroendoscopic third ventriculostomy in patients less than 1 year old. Pediatr Neurosurg 1998;29(02):73-76

50 Stan H, Kiss PA, Stan A, Florian IS. Neuroendoscopic surgery in hydrocephalus. Romanian Neurosurger 2012;19(04): 264-271

51 Warf BC, Tracy S, Mugamba J. Long-term outcome for endoscopic third ventriculostomy alone or in combination with choroid plexus cauterization for congenital aqueductal stenosis in African infants. J Neurosurg Pediatr 2012;10(02):108-111

52 Kulkarni AV, Drake JM, Kestle JR, Mallucci CL, Sgouros S, Constantini S; Canadian Pediatric Neurosurgery Study Group. Endoscopic third ventriculostomy vs cerebrospinal fluid shunt in the treatment of hydrocephalus in children: a propensity scoreadjusted analysis. Neurosurgery 2010;67(03):588-593

53 Balthasar AJ, Kort H, Cornips EM, Beuls EA, Weber JW, Vles JS. Analysis of the success and failure of endoscopic third ventriculostomy in infants less than 1 year of age. Childs Nerv Syst 2007;23(02):151-155

54 Warf BC. Hydrocephalus in Uganda: the predominance of infectious origin and primary management with endoscopic third ventriculostomy. J Neurosurg 2005;102(1, Suppl):1-15

55 Stan H, Popa C, Iosif A, Nistor S. Combined endoscopically guided third ventriculostomy with prepontine cistern placement of the ventricular catheter in a ventriculo-peritoneal shunt: technical note. Minim Invasive Neurosurg 2007;50(04):247-250

56 Spennato P, Tazi S, Bekaert O, Cinalli G, Decq P. Endoscopic third ventriculostomy for idiopathic aqueductal stenosis. World Neurosurg 2013;79(2, Suppl):21.e13-21.e20

57 Fukuhara T, Vorster SJ, Luciano MG. Risk factors for failure of endoscopic third ventriculostomy for obstructive hydrocephalus. Neurosurgery 2000;46(05):1100-1111

58 Bognar L, Markia B, Novak L. Retrospective analysis of 400 neuroendoscopic interventions: the Hungarian experience. Neurosurg Focus 2005;19:E10

59 Koch-Wiewrodt D, Wagner W. Success and failure of endoscopic third ventriculostomy in young infants: Are there different age distributions? Childs Nerv Syst 2006;22(12):1537-1541

60 Sacko O, Boetto S, Lauwers-Cances V, Dupuy M, Roux FE. Endoscopic third ventriculostomy: outcome analysis in 368 procedures. J Neurosurg Pediatr 2010;5:68-74 